\title{
A PRODUÇÃO ACADÊMICA DA FORMAÇÃO DE PROFESSORES NA EDUCAÇÃO PROFISSIONAL
}

\author{
I. M. S. P. CARNEIRO ${ }^{1 *}$, M. M. D. CAVALCANTE ${ }^{2}$ \\ ${ }^{1}$ Instituto Federal de Educação, Ciência e Tecnologia - IFCE , ${ }^{2}$ Universidade Estadual do Ceará - UECE \\ isabelmsaid@yahoo.com.br ${ }^{*}$ \\ Submetido 06/07/2017 - Aceito 05//07/2018 \\ DOI: $10.15628 /$ holos.2018.5953
}

\begin{abstract}
RESUMO
Este trabalho apresenta o cenário da produção acadêmica brasileira sobre a formação de professores da Educação Profissional e Tecnológica (EPT). O mapeamento dos trabalhos acadêmicos foi realizado, em setembro/2014, no banco de dados de dissertações e teses do portal da Coordenação de Aperfeiçoamento de Pessoal de Nível Superior (CAPES), na sessão de periódicos da CAPES, base de dados Scielo, nas reuniões anuais da Associação Nacional de Pós-Graduação e Pesquisa em Educação (ANPED) e nos Encontros de
\end{abstract}

\begin{abstract}
Didática e Prática de Ensino (ENDIPE). Em relação ao recorte temporal, definimos o período entre 2005 e 2014. Os estudos analisados destacam a importância das instituições de ensino criarem espaços de formação continuada, assumindo a responsabilidade de sustentar o desenvolvimento profissional dos professores e reforçam a necessidade de uma base epistemológica e metodológica fundamentar essa formação.
\end{abstract}

PALAVRAS-CHAVE: Formação de professores, Desenvolvimento profissional, Educação Profissional.

\section{THE ACADEMIC PRODUCTION ON THE TRAINING OF TEACHERS INVOCATIONAL EDUCATION}

\begin{abstract}
This paper presents the scenario of Brazilian academic production on the training of teachers inVocational and Technological Education. In September/2014, the skimming process on the data was done throughout the thesis and dissertations database of Coordenação de Aperfeiçoamento de Pessoal de Nível Superior (CAPES),the CAPES journals section, Scielo database, the annual meetings of Associação Nacional de Pós-Graduação e Pesquisa em Educação (ANPED), and Encontros de Didática e Prática de Ensino (ENDIPE). Theperiod of time analyzed is between 2005 and 2014. The studies approachedhighlight the importance of creating moments regarding the continuing training, assuming the responsibility to support the professional development of teachers, likewise,they reinforce the necessityof epistemological and methodological basis in order to do so.
\end{abstract}

KEYWORDS: training of teachers; Professional Development; technological education 


\section{INTRODUÇÃO}

Este trabalho tem como objetivo apresentar o cenário da produção acadêmica sobre a formação de professores no âmbito da Educação Profissional e Tecnológica (EPT) no Brasil. Tratase de uma etapa exploratória de uma pesquisa cujo tema é a formação pedagógica e a práxis dos Professores da EPT, de nível superior, desenvolvida no âmbito do Programa de Pós-Graduação de Educação da Universidade Estadual do Ceará (PPGE/UECE).

As discussões sobre a importância da formação pedagógica de professores para a EPT têm se ampliado nos últimos anos. A intensidade de tais discussões se coloca a partir das transformações sociais, políticas e econômicas que vêm ocorrendo no mundo, impulsionadas, principalmente, pelas novas demandas postas pelo que tem sido chamado de Revolução da Tecnologia da Informação e da Comunicação (CASTELLS, 1999). Esse cenário revela que os avanços na comunicação, na informática e as outras mudanças tecnológicas e científicas têm influenciado os vários sistemas de organização do trabalho e das relações profissionais, como que indicando novas demandas em relação à profissionalização de professores.

A preocupação com a formação inicial e continuada para a docência foi explicitada e fortalecida a partir da promulgação da Lei de Diretrizes e Bases da Educação Nacional (LDB) no 9.394/96, que passou a exigir, para o exercício docente na Educação Básica, formação em nível superior em cursos regulares de graduação plena (licenciatura) (art. 62). O referido instrumento legal também prever seu art. 66 que "a preparação para o exercício do magistério superior far-se-á em nível de pós-graduação, prioritariamente em programas de mestrado e doutorado."(BRASIL, 1996). Entretanto, não há uma abordagem expressa na LDB/96 acerca da formação docente para a EPT em nível de graduação, ficando esta submissa às orientações gerais de outras modalidades de ensino.

No intuito de aprofundarmos nossa compreensão acerca dessa temática, surgiu o interesse em realizar o mapeamento dos estudos acadêmicos que versam sobre o assunto da Educação Profissional e sua interface com a formação dos professores. Esse mapeamento configurou um caminho necessário para evidenciar nosso Estado da Questão (EQ) que tem a finalidade de "levar o pesquisador a registrar, a partir de um rigoroso levantamento bibliográfico, como se encontra o tema ou objeto de sua investigação no estado atual da ciência ao seu alcance." (NÓBREGATHERRIEN; THERRIEN, 2004, p.7). Nesse sentido, o EQ possibilita ao pesquisador conhecer o panorama de pesquisas na sua área de interesse, além de fornecer elementos que o ajudam a delimitar seu objeto de estudo, redefinir seus objetivos, identificar suas categorias teóricas, dentre outros aspectos.

A realização desta pesquisa parte do pressuposto de que é necessário uma formação didático-pedagógica formal dos professores bacharéis e tecnólogos, com aspectos teóricos e práticos articulados, para consecução de um trabalho crítico e reflexivo. Tal formação poderá contribuir para a concretização deseu trabalho, aliando as capacidades de pensar, planejar, refletir, criar e avaliar à capacidade de agir, na medida que pensar e fazer são dimensões da práxis docente. Consideramos, assim, que a ausência dessa formação pode levá-los a terem uma prática 
técnico-instrumental na sala de aula, viabilizando aos estudantes uma formação unilateral, voltada somente para o mercado de trabalho.

Diante dessas considerações, apresentamos a seguir o caminho percorrido na construção do nosso estudo, destacando sua contribuição para o aprofundamento da temática:"formaçãopedagógica de professores para EPT, de nível superior".

\section{O CENÁRIO ATUAL dA FORMAÇÃo de PROFESSORES PARA A EDUCAÇÃo PROFISSIONAL}

As discussões sobre a formação de professores para EPT a partir dos anos 2000 crescem no âmbito do desenvolvimento econômico e social do país em que a Educação Profissional e Tecnológica (EPT) passa a ser uma das estratégias importantes para combater o desemprego e fazer frente às mudanças tecnológicas, embora estas, na prática, não tenham tomado o efeito esperado. (KUENZER, 2006). Esse cenário é marcado pela tentativa de definição de políticas públicas para essa modalidade educacional, expressas aqui pelos marcos legais.

O tema em discussão logo aparece no Plano Nacional de Educação (Lei no 10.172/2001) que buscava, no período de 10 anos, uma melhoria na qualidade de ensino da Educação Básica e da Educação Superior, uma redução nas desigualdades sociais e regionais e uma democratização da gestão da educação pública. Mas, no que diz respeito à "Educação Tecnológica e Formação Profissional", podemos afirmar que não há uma proposta de oferta de cursos de licenciatura específicos para a EPT o que poderia contribuir para o reconhecimento da práxis docente no ensino tecnológico que envolve um campo de conhecimento próprio.

O tema da formação de professores para a EPT, nos anos seguintes, insere-se no amplo debate nacional sobre o papel da educação profissional como parte de um projeto governamental de desenvolvimento do país, comprometido com a justiça social e a distribuição de renda. Em 2003, ocorreu o "Seminário Nacional de Educação Profissional e Tecnológica: concepções, experiências, problemas e propostas", promovido pela Secretaria de Educação Média e Tecnológica (SEMTEC), em parceria com o Ministério da educação, cuja intenção foi buscar elementos para a definição, estruturação e materialização de uma política nacional de EPT. As discussões realizadas no seminário propiciaram a difusão do entendimento de que é preciso buscar um novo ordenamento econômico, político e educacional na premissa de contribuir efetivamente na "orientação do enfrentamento da vulnerabilidade a que estão expostos o país e parcelas significativas da sociedade brasileira." (BRASIL, 2003. p.3).

Em 2004, o Ministério da Educação em conjunto com a SEMTEC, agora denominada de Secretaria de Educação Profissional e Tecnológica (SETEC), lança o documento, intitulado "Proposta em discussão: Políticas Públicas para a Educação Profissional e Tecnológica" com a intenção de estabelecer diretrizes e definir políticas públicas para a EPT. Esse documento buscou acolher e consolidar os conteúdos e proposições do Seminário Nacional de Educação Profissional realizado em 2003 e teve o cuidado de resgatar as concepções e princípios gerais que deverão 
nortear essa modalidade de ensino, tendo como base o compromisso "com a redução das desigualdades sociais, o desenvolvimento socioeconômico, a vinculação à educação básica e a uma escola pública de qualidade." (BRASIL, MEC/SETEC, 2004, p.5).

Em 2006, o Conselho Pleno do CNE aprovou o Parecer no 05/2006 que prevê a oferta de cursos de licenciaturas destinados à formação de professores para a EPT organizados em habilitações especializadas por componentes curriculares para o caso do ensino médio integrado, ou por campo de conhecimento ou campo de atuação profissional, no caso da educação profissional, conforme indicado nas Diretrizes Curriculares pertinentes.

As reflexões de Kuenzer (2008) sobre o Parecer no 05/2006 foram apresentadas no Simpósio "Educação Superior em Debate: Formação de Professores para a Educação Profissional e Tecnológica", evento realizado em setembro de 2006, e organizado pela SETEC/MEC e o Instituto Nacional de Estudos e Pesquisas (INEP). Na ocasião, a referida autora defende a importância da oferta de licenciatura de educação profissional por campo de conhecimento e/ou profissional, considerando que deve "haver vinculação entre a licenciatura e a formação técnica de nível médio, seja médio integrado, ou técnico concomitante ou sequencial, mas com alguma direção para a área que ensinará. E também experiência profissional prévia". (KUENZER, 2008, p.35).

O pensamento de Kuenzer (2008) deixa entrever que a formação de professores para atuar na educação profissional, inclusive, de nível superior, implica a necessidade de formação científico-tecnológica, sócio-histórica e pedagógica, a ser adquirida em cursos de licenciatura, em articulação com a formação específica para o trabalho. Nesse sentido, a experiência profissional no mundo do trabalho é fundamental, pois é por meio dela que se adquirem conhecimentos empíricos sobre a área a ser ensinada.

Esse pensamento ganhou expressão no cenário educacional quando, em 2007, a SETEC/MEC, por intermédio do Departamento de Políticas e Articulações Institucionais constituiu um "Grupo de Trabalho "Formação de Professores para a Educação Profissional e Tecnológica", sob a coordenação de Lucília Machado, envolvendo pesquisadores e gestores, com o objetivo de diagnosticar e propor alternativas para o enfrentamento da problemática da formação dos professores de disciplinas profissionalizantes. As discussões desse grupo foram sistematizadas no documento "Diferenciais Inovadores na Formação de Professores para a Educação Profissional" que apontaram as licenciaturas como essenciais nesse processo formativo por serem:

[...] o espaço privilegiado da formação docente inicial e pelo importante papel que podem ter na profissionalização docente para o desenvolvimento de pedagogias apropriadas às especificidades da educação profissional, o intercâmbio de experiências no campo da educação profissional, o desenvolvimento da reflexão pedagógica sobre a prática docente nesta área, o fortalecimento do elo entre ensino-pesquisa-extensão, pensar a profissão, as relações de trabalho e de poder nas instituições escolares, a responsabilidade dos professores etc. (MACHADO, 2008, p.8)

Com base nessa compreensão, ressaltamos que faz parte do processo de formação didático-pedagógica dos professores da EPT a reflexão crítica (individual e coletiva) dos docentes 
sobre as suas práticas que permite a análise de suas teorias implícitas de ensino, "seus esquemas de funcionamento, suas atitudes etc., realizando um processo constante de autoavaliação que oriente seu trabalho." (IMBERNÓN, 2000, p.49). Nessa perspectiva, a reflexão pedagógica sobre sua atuação profissional possibilita a formação de novas ações com vistas à reconstrução de saberes, tendo em vista que a experiência docente é espaço gerador e produtor de conhecimento.

A consideração de que o professor é um sujeito dotado de uma ação crítica e reflexiva, que tem consciência do seu fazer pedagógico, por meio da articulação entre os esquemas práticos e teóricos que os sustentam, é um indicativo de que a docência não é uma "atividade burocrática para a qual se adquire conhecimentos e habilidades técnico-mecânicas." (PIMENTA, 2009, p.18). Ao contrário, é uma profissão a qual exige capacitação própria específica, independente do nível de ensino ou da modalidade educacional.

Nesse sentido, o professor é um intelectual em processo contínuo de formação o qual emerge da análise das práticas pedagógicas e docentes em articulação com os contextos sociais e institucionais nos quais ocorrem. Dessa maneira, é necessário que o docente tenha compreensão dos princípios que estruturam as instituições de ensino e a prática em sala de aula, bem como tenha clareza dos motivos de suas escolhas como profissional cujas consequências políticas influenciam na vida dos estudantes. O processo de formação do professor, assim, extrapola o mero treinamento e o desenvolvimento das competências laborais.

Somada à reflexão crítica, a unidade ensino/pesquisa orientada para a responsabilidade social também se constitui como elemento fundamental no processo de formação didáticopedagógica do professor da EPT tendo em vista que através da relação indissociável entre ensino, pesquisa e extensão, o docente tem condições de compreender as inter-relações entre suas finalidades e sua materialização nas condições reais e objetivas tanto da instituição onde trabalha quando do seu entorno.

Apesar dos avanços das discussões em torno do papel das licenciaturas na formação de professores para EPT, essa modalidade de curso para esse campo de ensino ainda não é consenso na Câmara da Educação Básica (CEB) com a Câmara de Educação Superior (CEP) do Conselho Nacional de Educação (CNE). Com essa indefinição, a CEB do CNE normatizou, em alguma medida, a formação de professores para a EPT, mediante a Resolução no6/2012 que define as Diretrizes Curriculares Nacionais para Educação Profissional Técnica de Nível Médio. Em seu art. 40, a referida resolução estabelece que essa formação poderá ser realizada em "cursos de graduação, programas de licenciatura ou outras formas, em consonância com a legislação e com as normas específicas definidas pelo Conselho Nacional de Educação." (BRASIL, 2012).

Tal prerrogativa legal tem um papel relevante para o campo da educação profissional e tecnológica, pois fortalece a ideia de que a formação de professores para essa modalidade de ensino deve ocorrer em cursos de nível superior (graduação e programas de licenciatura). Mas a resolução no6/2012 ao permitir "outras formas" de formação inicial pode contribuir para a oferta de cursos aligeirados, improvisados e fragmentados.

Em consonância com as Diretrizes Curriculares Nacionais para a Educação Profissional Técnica de Nível Médio (Resolução no6/2012), o novo PNE (Lei no 13.005/2014) estabelece 
estratégias que visam o desenvolvimento de diferentes maneiras de formação de professores para a EPT que valorizem a "experiência prática" e a oferta de cursos "voltados à complementação e certificação didático-pedagógica de profissionais experientes." (Estratégia 15.13). (BRASIL, 2014).

O PNE/2014, com essa estratégia, preconiza a necessidade de promover "modelos" de formação de professores para a Educação Profissional buscando atingir a meta (15) de assegurar que os professores que atuam na Educação Básica "possuam formação específica de nível superior, obtida em cursos de licenciatura na área de conhecimento em que atuam". (BRASIL, 2014). Conforme essa estratégia, esses "modelos de formação docente" devem valorizar a "experiência prática" do professor buscando privilegiar os saberes oriundos da sua trajetória profissional, ou seja, conhecimentos práticos que não provêm da formação dada pelas instituições de ensino superior, mas da prática docente cotidiana.

Na mesma lógica de valorização dos "saberes da experiência", a Lei no 13.415, de 16 de Fevereiro de 2017 considera que o "notório saber" dos profissionais da educação é aspecto suficiente para a atuação na formação técnica profissional de estudantes. Dessa maneira, admitese que arquitetos, engenheiros, médicos, contadores, advogados, dentre outros, atuem no campo da docência sem formação apropriada, ou seja, sem os conhecimentos didático-pedagógicos necessários ao exercício do magistério, podendo, assim, trazer empecilhos ao processo de ensinoaprendizagem.

Nesse contexto, entendemos que, nos últimos anos, tem-se avançado nas discussões em torno da constituição de uma política de formação inicial e continuada de professores para a EPT, porém, do ponto de vista legal, as ações propostas de formação docente se restringem a cursos especiais, emergenciais e aligeirados, bem como de prática docente baseada apenas na experiência profissional, fortalecendo a idéia de que não é necessária uma formação didáticopedagógica sólida para ensinar no campo da educação profissional e tecnológica.

\section{MAPEAMENTO DOS ESTUDOS: O CAMINHO PERCORRIDO}

O mapeamento dos trabalhos acadêmicos foi realizado, em setembro/2014, no banco de dados de dissertações e teses do portal da Coordenação de Aperfeiçoamento de Pessoal de Nível Superior (CAPES), na sessão de periódicos da CAPES, base de dados Scielo, nas reuniões anuais da Associação Nacional de Pós-Graduação e Pesquisa em Educação (ANPED) e nos Encontros de Didática e Prática de Ensino(ENDIPE).

A justificativa para a escolha da CAPES, da ANPED e do ENDIPE se sustenta no reconhecimento nacional que essas instituições desfrutam no campo científico da área da Educação. Em relação ao recorte temporal, definimos o período entre 2005 e 2014 por entendermos que a formação dos professores na Educação Profissional é uma preocupação recente dos educadores com a institucionalização do Programa de Expansão da Rede Federal de Educação Profissional e Tecnológica, a partir da Lei 11.195 de 2005.

Em relação aos descritores, utilizamos "Educação Profissional"; "Formação Pedagógica" e "Formação de Professores". Os achados desse levantamento no banco de dados de dissertações e 
teses da CAPES indicaram uma quantidade significativa de trabalhos sobre Formação de Professores e Educação Profissional, nos anos de 2011 e 2012, conforme apresentaremos no quadro $1 .{ }^{1}$

Quadro 1: Quantidade de pesquisas sobre formação docente e educação profissional no banco de teses da CAPES

(2011-2012)

\begin{tabular}{|l|c|c|c|}
\hline Descritor & Total & Dissertações & Teses \\
\hline Educação Profissional & 210 & 173 & 37 \\
\hline Formação Pedagógica & 69 & 56 & 13 \\
\hline Formação de Professores & 1068 & 882 & 186 \\
\hline Total & 1347 & 1111 & 236 \\
\hline
\end{tabular}

Fonte: Quadro elaborado com base em dados do portal da CAPES

Diante da quantidade de trabalhos encontrada em cada descritor, decidimos refazer o mapeamento dos estudos, estabelecendo a associação entre os descritores e seus cognatos, com o operador bolleano $a d^{2}$, no intuito de facilitar a identificação dos trabalhos relacionados à temática em estudo. Os descritores utilizados foram educação profissional, formação de professores, formação pedagógica, políticas de formação de professores, formação continuada, ensino técnico, formação docente, cursos técnicos, saberes docentes e saberes da docência. Em seguida, eliminamos as ocorrências de pesquisas que apareceram em mais de um descritor. Para identificar os trabalhos relacionados com o tema investigado, realizamos a leitura dos títulos e resumos, a partir dos seguintes critérios de escolha:

- Trabalhos acerca da Educação profissional técnica de nível médio e graduação tecnológica, na modalidade presencial;

- Como nosso estudo trata da relação entre a formação de professores eos cursos técnicos de caráter regular e contínuo e os cursos superiores de tecnologia, os trabalhos que tinham como campo empírico programas do governo federal não foram contemplados.

O quadro 2 mostra, no universo dos títulos e resumos analisados, a quantidade de trabalhos que tratam diretamente sobre a formação de professores para a Educação Profissional e Tecnológica, os quais, consequentemente, fizeram parte do nosso EQ.

\footnotetext{
${ }^{1}$ Nosso intuito era realizar o levantamento bibliográfico no período de 2005 a 2014, no entanto, o banco de teses da CAPES não estava atualizado, disponibilizando apenas trabalhos de 2011 e 2012.

2 O operador bolleanoand funcionada como a palavra "e", possibilitando restringir a amplitude da pesquisa e obter resultados mais precisos.
} 
Quadro 2: Quantitativo de dissertações e teses sobre formação docente e educação profissional e tecnológica banco de teses da CAPES (2011-2012)

\begin{tabular}{|c|c|c|c|c|}
\hline \multirow[t]{2}{*}{ Descritor } & \multirow{2}{*}{$\begin{array}{l}\text { Trabalhos } \\
\text { localizados }\end{array}$} & \multicolumn{2}{|c|}{ Trabalhos sobre a temática } & \multirow[t]{2}{*}{ Total } \\
\hline & & Dissertações & Teses & \\
\hline $\begin{array}{l}\text { Educação Profissional and formação } \\
\text { de professores }\end{array}$ & 51 & 2 & 4 & 6 \\
\hline $\begin{array}{l}\text { Educação Profissional and Formação } \\
\text { Pedagógica }\end{array}$ & 8 & 1 & 1 & 2 \\
\hline $\begin{array}{l}\text { Educação Profissional e políticas de } \\
\text { Formação de Professores }\end{array}$ & 6 & - & - & - \\
\hline $\begin{array}{l}\text { Educação Profissional and Formação } \\
\text { Continuada }\end{array}$ & 22 & 1 & - & 1 \\
\hline $\begin{array}{l}\text { Ensino técnico and formação de } \\
\text { professores }\end{array}$ & 6 & 1 & - & 1 \\
\hline $\begin{array}{l}\text { Ensino técnico and formação } \\
\text { docente }\end{array}$ & 13 & 1 & - & 1 \\
\hline $\begin{array}{l}\text { Ensino técnico and formação } \\
\text { pedagógica }\end{array}$ & 4 & - & - & - \\
\hline $\begin{array}{l}\text { Ensino técnico and políticas de } \\
\text { formação de professores }\end{array}$ & - & - & - & - \\
\hline $\begin{array}{l}\text { Ensino técnico and formação } \\
\text { continuada }\end{array}$ & 3 & - & - & - \\
\hline $\begin{array}{l}\text { Cursos técnicos and formação de } \\
\text { professores }\end{array}$ & 10 & 1 & - & 1 \\
\hline $\begin{array}{lll}\text { Educação Profissional e saberes } \\
\text { docentes }\end{array}$ & 6 & 1 & - & 1 \\
\hline Total de trabalhos & 129 & 8 & 5 & 13 \\
\hline
\end{tabular}

Fonte: Quadro elaborado com base em dados do portal da CAPES.

De acordo com quadro 2, é possível visualizar que de um total de 129 trabalhos, apenas 13 tratam da formação docente da Educação Profissional e Tecnológica. Um número reduzido de trabalhos acerca dessa temática também foi encontrado na sessão de periódicos da CAPES, base de dados SciELO, no período de 2005 a 2014, como podemos visualizar no seguinte quadro 3:

Quadro 3: Quantitativo de artigos sobre formação docente e educação profissional e tecnológica - periódico da CAPES, base de dados SciELO(2005-2014)

\begin{tabular}{|l|c|c|c|}
\hline Descritor & $\begin{array}{c}\text { Artigos } \\
\text { encontrados }\end{array}$ & $\begin{array}{c}\text { Artigos sobre } \\
\text { a temática }\end{array}$ & Total \\
\hline $\begin{array}{l}\text { Educação Profissional and Formação de } \\
\text { Professores. }\end{array}$ & 3 & 1 & 1 \\
\hline $\begin{array}{l}\text { Educação Profissional and Formação } \\
\text { Pedagógica. }\end{array}$ & 2 & - & - \\
\hline $\begin{array}{l}\text { Educação Profissional e Políticas de } \\
\text { formação de Professores. }\end{array}$ & - & - & - \\
\hline Educação Profissional and Formação & 1 & - & - \\
\hline
\end{tabular}




\begin{tabular}{|l|l|l|l|}
\hline continuada. & & & \\
\hline $\begin{array}{l}\text { Ensino Técnico and Formação de } \\
\text { Professores. }\end{array}$ & - & - & - \\
\hline Ensino Técnico and Formação Pedagógica. & - & - & - \\
\hline $\begin{array}{l}\text { Ensino Técnico and Políticas de Formação de } \\
\text { Professores. }\end{array}$ & - & - & - \\
\hline Ensino Técnico and Formação Continuada. & - & - & - \\
\hline $\begin{array}{l}\text { Cursos Técnicos and Formação de } \\
\text { Professores. }\end{array}$ & & - & - \\
\hline Educação Profissional and Saberes docentes. & 1 & 1 & 1 \\
\hline Educação Profissional e saberes da docência & 8 & 3 & 1 \\
\hline Total de trabalhos & 1 & 1 & 3 \\
\hline
\end{tabular}

Fonte: Quadro elaborado com base em dados no portal Scielo.

Além do mapeamento dos estudos realizado no portal da CAPES, inventariamos também nas reuniões anuais da ANPED os artigos publicados, nas modalidades trabalhos e pôsteres, mais precisamente, no GT-8 Formação de Professores e GT-9 Educação Profissional. Inicialmente, as buscas foram realizadas no período de 2005 a 2013³, porém, como nesse período só foram encontrados dois trabalhos relacionados à nossa temática (nos anos de 2006 e 2012), decidimos ampliar as buscas, a partir das produções do ano 2000, conforme disponibilidade para consulta no site da ANPED, o que nos permitiu encontrar em 2004, uma publicação que tinham relação com o nosso interesse de investigação. O quadro 4 a seguir apresenta os achados dessa busca, estabelecendo " $T$ " para Trabalho e " $P$ " para Pôster:

Quadro 4: Quantitativo de artigos sobre formação docente e educação profissional e tecnológica publicados nas reuniões anuais da ANPED (2000-2013)

\begin{tabular}{|c|c|c|c|c|c|c|}
\hline \multirow{2}{*}{$\begin{array}{c}\text { Reuniã } \\
\text { o }\end{array}$} & \multirow{2}{*}{$\begin{array}{r}\text { Ano } \\
2000 \\
\end{array}$} & \multicolumn{2}{|c|}{$\begin{array}{c}\text { GT-8 } \\
\text { Formação } \\
\text { de Professores }\end{array}$} & \multicolumn{2}{|c|}{$\begin{array}{c}\text { GT-9 } \\
\text { Trabalho e } \\
\text { Educação } \\
\end{array}$} & \multirow{2}{*}{$\begin{array}{c}\begin{array}{c}\text { Trabalhos } \\
\text { sobre a } \\
\text { temática }\end{array} \\
-\end{array}$} \\
\hline & & $\mathrm{T}-11$ & $\mathrm{P}-7$ & T-10 & $\mathrm{P}-4$ & \\
\hline $24 \underline{a}$ & 2001 & $\mathrm{~T}-17$ & $\mathrm{P}-12$ & T-16 & P-4 & - \\
\hline 25 a & 2002 & $\mathrm{~T}-10$ & P-6 & T-10 & P-1 & - \\
\hline $26 \underline{a}$ & 2003 & $\mathrm{~T}-12$ & P-6 & T-16 & P-2 & - \\
\hline $27 \underline{a}$ & 2004 & $\mathrm{~T}-22$ & $\mathrm{P}-6$ & T-19 & $\mathrm{P}-2$ & $1-\mathrm{GT} 8$ \\
\hline $28 \underline{a}$ & 2005 & T-45 & $\mathrm{P}-10$ & T-19 & $\mathrm{P}-7$ & - \\
\hline $29 a$ & 2006 & T-29 & $\mathrm{P}-8$ & T-15 & $\mathrm{P}-3$ & $1-\mathrm{GT} 8$ \\
\hline 30 a & 2007 & T-31 & $\mathrm{P}-8$ & T-17 & $\mathrm{P}-1$ & - \\
\hline 31 a & 2008 & $\mathrm{~T}-18$ & $P-8$ & $\mathrm{~T}-12$ & $P-4$ & - \\
\hline $32^{a}$ & 2009 & $\mathrm{~T}-21$ & $\mathrm{P}-5$ & $\mathrm{~T}-12$ & $\mathrm{P}-2$ & - \\
\hline $33 \underline{a}$ & 2010 & $\mathrm{~T}-21$ & $\mathrm{P}-3$ & $\mathrm{~T}-11$ & $\mathrm{P}-3$ & - \\
\hline
\end{tabular}

${ }^{3}$ Não realizamos a busca no ano de 2014, pois não houve reunião da ANPED neste ano. 


\begin{tabular}{|l|l|l|l|l|l|l|}
\hline 34 a & 2011 & T-22 & P-8 & T-17 & P-3 & - \\
\hline 35a & 2012 & T-22 & P-12 & T-13 & P-2 & $2-$ GT 8 \\
\hline 36a & 2013 & T- 18 & P-9 & T-10 & P-4 & - \\
\hline \multicolumn{2}{|l|}{ Total de trabalhos } & $\mathbf{1 9 9}$ & $\mathbf{1 0 8}$ & $\mathbf{1 9 7}$ & $\mathbf{4 2}$ & $\mathbf{4}$ \\
\hline
\end{tabular}

Fonte: Quadro elaborado com base em dados no portal da ANPED.

O resultado do levantamento dos artigos científicos nas reuniões anuais da ANPED indica que a temática "formação docente" vem sendo, nos últimos anos tema de interesse de muitos pesquisadores. Entretanto, observamos, assim como no portal da CAPES, que as pesquisas na área de formação de professores para EPT ainda são incipientes, com apenas 4 trabalhos publicados no GT 8- Formação de professores. Não foram encontrados no GT 9 - Trabalho e Educação, artigos com foco na formação docente da EPT, apesar de, historicamente, possuir um acúmulo de discussão acerca dos fins e objetivos da educação profissional.

Assim como a ANPED, o Encontro Nacional de Didática e Prática de Ensino(ENDIPE), também é um evento bastante conceituado no campo da Educação. Como este ocorre a cada dois anos, realizamos as buscas a partir do ano 2000 no intuito de identificar uma maior quantidade de trabalhos relacionados à temática em estudo. 0 resultado é apresentado no quadro 5 :

Quadro 5: Quantitativo de artigos sobre formação docente e educação profissional e tecnológica - ENDIPE (2000$2014^{4}$ )

\begin{tabular}{|l|l|c|c|}
\hline Edição do ENDIPE & Ano & $\begin{array}{c}\text { Trabalhos } \\
\text { publicados }\end{array}$ & $\begin{array}{c}\text { Trabalhos } \\
\text { sobre a temática }\end{array}$ \\
\hline $\mathrm{X}$ & 2000 & 323 & - \\
\hline $\mathrm{XI}$ & 2002 & 673 & - \\
\hline $\mathrm{XII}$ & 2004 & 1335 & 1 \\
\hline $\mathrm{XIII}$ & 2006 & 779 & - \\
\hline $\mathrm{XIX}$ & 2008 & 169 & 4 \\
\hline $\mathrm{XV}$ & 2010 & 637 & 1 \\
\hline $\mathrm{XVI}$ & 2012 & 1.668 & 5 \\
\hline $\mathrm{XVII}$ & 2014 & 1012 & 12 \\
\hline \multicolumn{2}{|c|}{ Total de trabalhos } & 6.596 & \\
\hline
\end{tabular}

Fonte: Quadro elaborado com base em dados dos CD's do evento.

De acordo com os estudos mapeados através do portal da CAPES e nos eventos ANPED e ENDIPE, identificamos 13 dissertações e teses, 3 artigos publicados em periódicos e 11 artigos publicados nos referidos eventos que tem relação com a formação de professores da educação profissional e tecnológica - EPT.

\footnotetext{
${ }^{4}$ Não foram analisados os artigos encontrados no XVII ENDIPE/2014, pois até o início de Janeiro de 2015, estes ainda não tinham sido disponibilizados pela organização do evento.
} 
Após esse levantamento, apresentamos a seguir a análises dos trabalhos que tem como objeto de investigação a formação de professores e sua relação com a educação profissional e tecnológica. Os trabalhos encontrados foram organizados e analisados por temática, permitindo uma melhor compreensão de suas problemáticas e objetivos, quais sejam: constituição da docência, formação de professores na perspectiva da cultura docente, contribuição da formação continuada para a prática docente e políticas de formação docente.

\section{A FORMAÇÃO DE PROFESSORES PARA EDUCAÇÃO PROFISSIONAL E TECNOLÓGICA: A ANÁLISE DOS ACHADOS}

Neste tópico, apresentaremos a análise dos estudos encontrados sobre a formação de professores da Educação Profissional e Tecnológica - EPT. Primeiramente, organizamos os trabalhos em um quadro identificando os seguintes aspectos: ano, local de publicação, instituição, tipo de trabalho, autor e título, conforme podemos visualizar a seguir:

Quadro 6: Síntese dos trabalhos sobre a formação docente da EPT

\begin{tabular}{|c|c|c|c|c|c|}
\hline Ano & $\begin{array}{l}\text { Local de } \\
\text { Publicação }\end{array}$ & Instituição & $\begin{array}{l}\text { Tipo de } \\
\text { trabalho }\end{array}$ & Autor es) & Título \\
\hline 2004 & ANPED & PUC/SP & Artigo & $\begin{array}{l}\text { Gomes, Heloisa } \\
\text { Maria }\end{array}$ & $\begin{array}{l}\text { Formando professores para a } \\
\text { educação profissional }\end{array}$ \\
\hline 2004 & ENDIPE & CEFET/MG & Artigo & $\begin{array}{l}\text { Araújo, Tânia } \\
\text { Márcia Fernandes } \\
\text { de }\end{array}$ & $\begin{array}{l}\text { A formação continuada segundo } \\
\text { os professores do ensino técnico }\end{array}$ \\
\hline 2006 & ANPED & CEFET/MG & Artigo & Burnier, Suzana & $\begin{array}{l}\text { A docência na Educação } \\
\text { Profissional }\end{array}$ \\
\hline 2006 & ENDIPE & CEFET/MG & Artigo & $\begin{array}{l}\text { Oliveira, Maria Rita } \\
\text { Sales }\end{array}$ & $\begin{array}{l}\text { Formação e profissionalização } \\
\text { dos professores do ensino } \\
\text { técnico }\end{array}$ \\
\hline 2010 & ENDIPE & UFSM & Artigo & $\begin{array}{l}\text { Quadros, } \\
\text { Claudemir de } \\
\text { Santos, Leila Maria } \\
\text { Araújo } \\
\text { Rodrigues, Maria } \\
\text { Luiza } \\
\text { Barichello, Marta } \\
\text { Roseli de Azeredo }\end{array}$ & $\begin{array}{l}\text { Interdisciplinaridade na formação } \\
\text { pedagógica de docentes para a } \\
\text { educação profissional: algumas } \\
\text { aproximações }\end{array}$ \\
\hline 2010 & ENDIPE & $\begin{array}{l}\text { Fundação } \\
\text { Helena } \\
\text { Antipoff }\end{array}$ & Artigo & $\begin{array}{l}\text { Durães, } \quad \text { Marina } \\
\text { Nunes }\end{array}$ & $\begin{array}{l}\text { O professor da educação } \\
\text { profissional: } \\
\text { formação e relação com a } \\
\text { docência }\end{array}$ \\
\hline
\end{tabular}




\begin{tabular}{|c|c|c|c|c|c|}
\hline 2010 & ENDIPE & CEFET/MG & Artigo & $\begin{array}{l}\text { Burnier, Suzana; } \\
\text { Gariglio, José } \\
\text { Ângelo }\end{array}$ & $\begin{array}{l}\text { Uma aproximação inicial aos } \\
\text { saberes da docência da educação } \\
\text { profissional }\end{array}$ \\
\hline 2010 & ENDIPE & PUC/SP & Artigo & Perez, Deivis & $\begin{array}{l}\text { Paradigmas de formação: estudo } \\
\text { sobre um modelo de capacitação } \\
\text { e desenvolvimento de } \\
\text { professores para a educação } \\
\text { profissional }\end{array}$ \\
\hline 2010 & $\begin{array}{l}\text { Cadernos de } \\
\text { pesquisa }\end{array}$ & UFBA & Artigo & $\begin{array}{l}\text { Vera, Fartes; } \\
\text { Adriana Paula Q. } \\
\text { Oliveira, santos }\end{array}$ & $\begin{array}{l}\text { Saberes, identidades, autonomia } \\
\text { na cultura docente da educação } \\
\text { profissional e tecnológica. }\end{array}$ \\
\hline 2011 & $\begin{array}{l}\text { Revista } \\
\text { Educação e } \\
\text { Sociedade }\end{array}$ & UNICAMP & Artigo & $\begin{array}{l}\text { Machado, Lucília } \\
\text { Regina de Souza }\end{array}$ & $\begin{array}{l}\text { O desafio da formação dos } \\
\text { professores para a EPT e PROEJA. }\end{array}$ \\
\hline 2011 & $\begin{array}{l}\text { Portal da } \\
\text { CAPES }\end{array}$ & PUC/PR & $\begin{array}{l}\text { Dissertaç } \\
\text { ão }\end{array}$ & $\begin{array}{l}\text { Orso, Ana Paula } \\
\text { Grochocki }\end{array}$ & $\begin{array}{l}\text { As políticas educacionais de } \\
\text { formação de professores dos } \\
\text { cursos técnicos em nível médio: } \\
\text { cursos profissionalizantes no } \\
\text { Paraná. }\end{array}$ \\
\hline 2011 & $\begin{array}{l}\text { Portal da } \\
\text { CAPES }\end{array}$ & UNICAMP & Tese & $\begin{array}{l}\text { Oliveira, } \\
\text { NeldaPlentz De. }\end{array}$ & $\begin{array}{l}\text { Formação continuada de } \\
\text { professores e o desenvolvimento } \\
\text { de currículos integrados na } \\
\text { educação profissional } \\
\text { tecnológica. }\end{array}$ \\
\hline 2011 & $\begin{array}{l}\text { Portal da } \\
\text { CAPES }\end{array}$ & UNICAMP & $\begin{array}{l}\text { Dissertaç } \\
\text { ão }\end{array}$ & $\begin{array}{l}\text { Martins, Leticia } \\
\text { Aparecida }\end{array}$ & $\begin{array}{l}\text { Trajetória de constituição da } \\
\text { docência na educação } \\
\text { profissional. }\end{array}$ \\
\hline 2011 & $\begin{array}{l}\text { Portal da } \\
\text { CAPES }\end{array}$ & PUC/PR & $\begin{array}{l}\text { Dissertaç } \\
\text { ão }\end{array}$ & Carpim, Lucymara & $\begin{array}{l}\text { Formação pedagógica dos } \\
\text { professores do ensino técnico: } \\
\text { caminhos históricos para um } \\
\text { paradigma da complexidade. }\end{array}$ \\
\hline 2011 & $\begin{array}{l}\text { Portal da } \\
\text { CAPES }\end{array}$ & $\begin{array}{l}\text { Centro } \\
\text { Universitár } \\
\text { io La Salle }\end{array}$ & $\begin{array}{l}\text { Dissertaç } \\
\text { ão }\end{array}$ & $\begin{array}{l}\text { Santos, patrícia } \\
\text { penha dos. }\end{array}$ & $\begin{array}{l}\text { Formação continuada de } \\
\text { educadores: um olhar focado na } \\
\text { educação profissional e nas } \\
\text { movimentações das tecnologias } \\
\text { da comunicação e informação. }\end{array}$ \\
\hline 2011 & $\begin{array}{l}\text { Portal da } \\
\text { CAPES }\end{array}$ & UFRGS & Tese & $\begin{array}{l}\text { Simionato, } \\
\text { Margareth } \\
\text { Fadanelli }\end{array}$ & $\begin{array}{l}\text { A formação do professor do } \\
\text { ensino técnico e a cultura } \\
\text { docente. }\end{array}$ \\
\hline 2011 & $\begin{array}{l}\text { Portal da } \\
\text { CAPES }\end{array}$ & UFMG & Tese & $\begin{array}{l}\text { Barbacovi, Lecir } \\
\text { Jacinto }\end{array}$ & $\begin{array}{l}\text { O professor de educação } \\
\text { profissional e a conectividade } \\
\text { orgênica entre formação e } \\
\text { pratica docente. }\end{array}$ \\
\hline
\end{tabular}




\begin{tabular}{|c|c|c|c|c|c|}
\hline 2011 & $\begin{array}{l}\text { Portal da } \\
\text { CAPES }\end{array}$ & UFPR & Tese & $\begin{array}{l}\text { Urbanetz, Sandra } \\
\text { Terezinha }\end{array}$ & $\begin{array}{l}\text { A constituição do docente para a } \\
\text { educação profissional }\end{array}$ \\
\hline 2012 & $\begin{array}{l}\text { Portal da } \\
\text { CAPES }\end{array}$ & PUC/RS & Tese & $\begin{array}{l}\text { Fortes, Maria } \\
\text { Carolina. }\end{array}$ & $\begin{array}{llr}\text { Entrelaçados } & \text { de vidas: } & \text { A } \\
\text { constituição da docência } & \text { na } \\
\text { educação } & \text { profissional } & \text { e } \\
\text { tecnológica. } & & \end{array}$ \\
\hline 2012 & $\begin{array}{l}\text { Portal da } \\
\text { CAPES }\end{array}$ & UFU & Tese & $\begin{array}{l}\text { Costa, maria Adelia } \\
\text { da. }\end{array}$ & $\begin{array}{l}\text { Políticas de formação de } \\
\text { professores para a educação } \\
\text { profissional e tecnológica: } \\
\text { cenários contemporâneos. }\end{array}$ \\
\hline 2012 & $\begin{array}{l}\text { Portal da } \\
\text { CAPES }\end{array}$ & UFPel & $\begin{array}{l}\text { Dissertaç } \\
\text { ão }\end{array}$ & $\begin{array}{l}\text { Cardoso, Aliana } \\
\text { Anghinoni. }\end{array}$ & $\begin{array}{l}\text { Professores? Sim! Os saberes } \\
\text { docentes e os professores da } \\
\text { educação profissional. }\end{array}$ \\
\hline 2012 & $\begin{array}{l}\text { Portal da } \\
\text { CAPES }\end{array}$ & UFSC & $\begin{array}{l}\text { Dissertaç } \\
\text { ão }\end{array}$ & Moreira, Alexandre & $\begin{array}{l}\text { Formação e atuação do bacharel- } \\
\text { professor na área de } \\
\text { telecomunicações do Instituto } \\
\text { Federal de Santa Catarina }\end{array}$ \\
\hline 2012 & $\begin{array}{l}\text { Portal da } \\
\text { CAPES }\end{array}$ & PUC/PR & $\begin{array}{l}\text { Dissertaç } \\
\text { ão }\end{array}$ & $\begin{array}{l}\text { Cunha, Marlise } \\
\text { Pinheiro da. }\end{array}$ & $\begin{array}{l}\text { Formação continuada do } \\
\text { professor do ensino técnico em } \\
\text { Estética }\end{array}$ \\
\hline 2012 & $\begin{array}{l}\text { Educação } \\
\text { em Revista. }\end{array}$ & UFMG & Artigo & $\begin{array}{l}\text { Gariglio, José } \\
\text { Ângelo; Burnier, } \\
\text { Suzana }\end{array}$ & $\begin{array}{l}\text { Saberes da docência na educação } \\
\text { profissional e tecnológica: um } \\
\text { estudo sobre o olhar dos } \\
\text { professores. }\end{array}$ \\
\hline 2012 & ANPED & \begin{tabular}{|l|} 
Faculdade \\
Senac \\
Pernambuc \\
o
\end{tabular} & Artigo & $\begin{array}{l}\text { Nunes, Terezinha } \\
\text { de Souza Ferraz }\end{array}$ & $\begin{array}{l}\text { A constituição da docência nos } \\
\text { cursos superiores de tecnologia: } \\
\text { implicações do discurso } \\
\text { pedagógico oficial }\end{array}$ \\
\hline 2012 & ANPED & IFPE & Artigo & $\begin{array}{l}\text { Paiva, Cantaluce; } \\
\text { Mércia Ferreira }\end{array}$ & $\begin{array}{l}\text { A identidade docente na } \\
\text { educação profissional: como se } \\
\text { forma o professor }\end{array}$ \\
\hline 2012 & ENDIPE & IFF/UFSM & Artigo & $\begin{array}{l}\text { Santos, Luciana } \\
\text { Dalla Nora dos.; } \\
\text { Fighera, Adriana } \\
\text { Claudia Martins; } \\
\text { Juchem, Luiza de } \\
\text { Salles }\end{array}$ & $\begin{array}{l}\text { A formação pedagógica do } \\
\text { professor da educação } \\
\text { profissional e tecnológica }\end{array}$ \\
\hline
\end{tabular}

Fonte: Elaboração das autoras.

De acordo com o quadro 6, percebemos que do total de 27 trabalhos, a maioria (18) é oriunda de instituições públicas, sendo 3 dissertações, 6 teses e 9 artigos. Em relação à distribuição geográfica dessas instituições, constatamos que as regiões sudeste e sul foram as que mais apresentaram produções científicas nessa área, com destaque para o CEFET/MG que 
publicou 4 trabalhos em eventos. Em contraposição à região nordeste que teve apenas uma tese de doutorado e dois artigos publicados em eventos.

Diante dessa constatação, realizamos a leitura na íntegra dos trabalhos, buscando identificar os objetos de investigação no âmbito da formação de professores da EPT. O conjunto de estudos analisados indicou a existência de quatro temáticas, ou seja, tendências de pesquisa nessa área, quais sejam: 1) saberes docentes e a constituição profissional dos professores; 2) a formação de professores na perspectiva da cultura docente; 3 ) influências e contribuições da formação continuada para a prática docente e 4) políticas de formação docente.

Considerando essas temáticas de pesquisa, apresentamos a seguir a análise dos trabalhos por tema, buscando destacar seus objetivos e resultados pertinentes ao nosso objeto de investigação. Nossa intenção, assim, é evidenciar a contribuição do nosso estudo para o campo da educação no que respeita à formação docente da Educação Profissional e Tecnológica (EPT).

\subsection{Saberes docentes e a constituição profissional dos professores}

A formação de professores da Educação Profissional e Tecnológica (EPT) analisada mediante os saberes docentes e os processos de constituição profissional dos professores trata-se de uma temática encontrada em dez trabalhos (BURNIER, 2006; MARTINS, 2011; URBANETZ, 2011; DURÃES, 2010; FORTES, 2012; CARDOSO, 2012; BURNIER; GARIGLIO, 2010; GARIGLIO; BURNIER, 2012; PAIVA, 2012; MOREIRA, 2012). Os autores partem das trajetórias de vida dos professores, como escolaridade, escolha profissional, relações intersubjetivas, saberes e habilidades adquiridos, mobilizados e construídos no exercício do magistério, dentre outros aspectos que envolvem seu contexto de trabalho.

Desses dez trabalhos, oito (BURNIER, 2006; MARTINS, 2011; URBANETZ, 2011; CARDOSO, 2012; GARIGLIO; BURNIER, 2012; PAIVA, 2012; MOREIRA, 2012; DURÃES, 2010) destacam preocupações com a ampliação de profissionais bacharéis e/ou tecnólogos que ingressam na docência sem uma formação pedagógica inicial, ou seja, sem ter estudado formalmente a educação, o papel do professor, bem como os processos de ensinar e aprender.

Gariglio e Burnier (2012), ancorados na epistemologia da prática, pretendem analisar, a partir das representações dos docentes que atuam no ensino técnico de diversas instituições de educação profissional (federais, estaduais e privadas), os saberes acionados e demandados pelos docentes nas suas atividades educativas e as concepções de formação profissional subjacentes a tais saberes. Os resultados desse estudo revelam que os professores bacharéis têm uma percepção sobre a formação inicial e continuada para o exercício da docência na educação profissional "distante da formação pedagógica e fortemente vinculada à experiência profissional no mercado de trabalho e em experiências de formação em cursos, eventos, palestras que tratam de temas relacionados às áreas específicas(tecnológica)." (GARIGLIO e BURNIER, 2012, p.228). Esses autores também confirmam a tese de que os saberes pedagógicos ocupam uma posição de menor statusna hierarquia dos saberes necessários a ensinar. 
A desvalorização dos conhecimentos pedagógicos se materializa de diferentes maneiras nas diferentes instituições de ensino. Martins (2011), as buscar investigar as trajetórias de constituição do saber de professoras nutricionistas que atuam em cursos técnicos, comenta que o processo seletivo para ingresso de novos professores na instituição tem valorizado os conhecimentos desses profissionais na área específica do conhecimento, em detrimento das questões pedagógicas. Para a referida autora, existe a "cultura da dimensão pedagógica da prática docente focada no desempenho didático", o que restringe o "pedagógico ao caráter instrumental da técnica." (p.16).

Considerando que os professores nutricionistas não foram preparados para ensinar, a pesquisa realizada por Martins (2011) revela que os processos de constituição das profissionais de Nutrição como docentes estão relacionados ao fato de carregarem uma habilidade própria e individual para exercer a docência; às suas referências teórico-metodológicas, fundamentadas nas práticas de ex-professores e colegas professores;às suas experiências no campo da Nutrição que Ihe conferem argumentos e sustentação para suas dinâmicas de sala; e aos seus desempenhos, abordagens e intervenções educativas aprimoradas ao longo de suas carreiras.Essa realidade também foi encontrada por Urbanetz (2011) quando investigou a trajetória pedagógica de engenheiros eletricistas que se tornaram professores da educação profissional.

Moreira (2012) ao analisar o processo de formação e a atuação de onze bacharéisprofessores na modalidade dos cursos Técnico Integrado de Nível Médio e Pós-Médio identifica que estes, mesmo sem uma formação pedagógica específica, "preferem se especializar nas áreas tecnológicas do que em estudos no campo educacional." (p.18). Eles contribuem, assim, para que o curso tenha um corpo docente "altamente qualificado" na sua área específica de conhecimento, em detrimento de uma prática pedagógica crítica e reflexiva.

As motivações que levam aos profissionais de diversas áreas a ingressarem na carreira docente foram abordadas nas pesquisas de Burnier (2006) e Durães (2010). A primeira buscou analisar as representações acerca do ofício junto a professores de escolas profissionalizantes de nível básico e técnico. E a segunda teve como objeto de análise o professor da Educação Profissional, sua formação, origem social e relação com a docência.

Os resultados das duas investigações revelam que os profissionais originários de diversas profissões não tiveram a docência como primeira opção profissional e consideram que o magistério, além da oportunidade de complementação salarial, oferece um ambiente de trabalho mais flexível, menos insalubre e estressante comparado ao da indústria, de onde vieram. Por outro lado, a partir do momento em que esses profissionais ingressam na carreira, são atraídos pelas relações que estabelecem, sobretudo, com os alunos, e que lhes proporcionam uma forte gratificação por se sentirem contribuindo para a formação de outras pessoas.

Considerando a escassez de investigações que se ocupam em compreender os docentes da educação profissional, a constituição de suas trajetórias como professores, a ausência de políticas específicas para sua formação e as suas condições de trabalho,Cardoso (2012) buscou desenvolver uma pesquisa no sentido de contribuir com a consolidação do campo de pesquisa sobre os docentes,seus saberes e sua profissão no âmbito da Educação Profissional e Tecnológica. A autora, 
ao buscar identificar os saberes que os professores mobilizam, adquirem e constroem ao longo de suas trajetórias profissionais, constata a existência de um conjunto de saberes que é específico dos professores da Educação Profissional os quais possibilitam que o professor alcance o seu principal objetivo, que é o de ensinar uma profissão.

Com a intenção de compreender como a docência se constitui nas trajetórias de professores que atua na educação profissional, Fortes (2012) também aponta que os saberes é elemento fundante dos processos constitutivos da docência que se estabelecem nos processos interacionais em diferentes tempos e espaços sociais, tais como vivências na cidade, formação acadêmica, experiência profissional em empresas, curso de formação pedagógica, reuniões pedagógicas, conselhos de classe, sala de aula etc.

Fortes (2012), assim como Cardoso (2012), alerta que a discussão dessa temática se encontra circunscrita pelos aspectos contextuais, a exemplo das mudanças históricas que a Educação Profissional e Tecnológica vem assumindo, bem como o processo de expansão e reorganização pelo qual tem passado a Rede Federal de Educação Profissional e Tecnológica nos últimos anos, os quais trazem como consequência a docência como um novo espaço profissional com formação nas áreas tecnológicas. Esse alerta nos chamou atenção visto que discutir a formação de professores da educação profissional significa compreender os processos formativos docentes nessa modalidade de ensino no âmbito nas tessituras das relações sociais, políticas e econômicas inerentes à sociedade capitalista.

Paiva (2011), ao buscar compreender como os professores do ensino técnico constituem sua identidade docente articulando os conhecimentos adquiridos na formação inicial com os saberes docentes no exercício da docência, contata que o professor da educação profissional se forma no seu próprio cotidiano de trabalho onde vivencia conflitos e situações diversas. Sua identidade docente, assim, se configura a partir da "reelaboração de conhecimentos e de novos saberes, evidenciando a existência de um saber que se constrói no próprio fazer, isto é, um saber tácito ou conhecimento prático adquirido nas experiências vividas e no exercício das atividades pedagógicas." (p.24).

Os estudos ora apresentados que tomaram como referência o campo dos saberes docentes e o processo de constituição profissional dos professores contribuíram para fortalecer nosso entendimento de que formação pedagógica inicial e continuada se faz necessária para o desenvolvimento profissional dos professores da Educação Profissional Tecnológica (EPT), diante da necessidade do professor ter, além do domínio do conteúdo específico, o conhecimento didático a partir do entendimento do mundo do trabalho.

Vislumbramos, assim, uma formação docente que leve em consideração às experiências anteriores dos professores tanto pessoais como profissionais, incluindo aquelas na indústria ou no setor de serviços;os programas permanentes de formação continuada nas instituições de ensino, abordando temas sobre o mercado de trabalho, os diferentes perfis dos jovens, a participação democrática nas instâncias institucionais, proporcionando uma sólida formação teórico-prática para o exercício da docência. 
Diante do exposto, ressaltamos que as pesquisas analisadas apontam que a formação pedagógica dos professores possibilita a estes uma compreensão dos processos educacionais para além das fronteiras de suas próprias experiências. Entendemos, assim, que essa formação contribui para o desempenho do professor na sala de aula minimizando os desafios e as dificuldades enfrentadas cotidianamente.

\subsection{A formação dos professores na perspectiva da cultura docente}

Este tópico tem como foco a discussão da formação de professores da Educação Profissional e Tecnológica (EPT) na perspectiva da cultura docente. Mesmo tendo similaridade com o tópico anterior (saberes docentes e a constituição profissional dos professores), optamos por dar destaque aqui aos trabalhos de Simionato (2011) e Fartes e Santos (2011), pois ao enfocarem a cultura docente nas instituições de ensino estabelecem relação com os saberes, a identidade, a autonomia do professor e o contexto, apontando novas perspectivas de investigações nessa área.

O estudo de Simionato (2011) busca analisara cultura docentee suas influências nas práticas e formação de professores que atuam em escolas técnicas privadas, bem como de candidatos a um programa especial de formação pedagógica numa instituição de ensino superior. Os dados dessa pesquisa revelam que as reformas educacionais quando chegam às escolas produzem nos professores um entendimento mais próximo do sentido de uma "educação voltada para o atendimento das necessidades do mercado do que para uma educação comprometida com a formação humana que tenha o trabalho como princípio educativo." (SIMIONATO, 2011, p.162).

Para Simonato (2011), os professores que iniciam a carreira docente além de não terem um acompanhamento sistemático em sua inserção profissional, não têm uma formação inicial e continuada que contribua para a reelaboração de suas concepções. Assim, elaboram suas crenças e constroem sua cultura docente "a partir de vivências e experiências próximas, sejam elas do contexto empresarial e de mercado de onde advém para a sala de aula, seja pela reprodução do que vivenciam no próprio contexto escolar sem ressignificações, sem colocar sob suspeita o que se apresenta." (p.162).

Na perspectiva da cultura profissional docente também encontramos o trabalho de Fartes e Santos (2011) que visa realizar a discussão dessa temática situando-a diante das alterações ocasionadas pelas políticas públicas para a educação profissional no cenário mais amplo das exigências, mudanças e crise global do capitalismo. Os autores realizam um estudo bibliográfico enfocando quatro teses relacionadas aos professores da Educação Profissional e Tecnológica, quais sejam: a primeira trata da defesa de que as estruturas pedagógicas e organizacionais têm resultado em dilemas e paradoxos que interferem significativamente na cultura profissional dos docentes; a segunda trata da construção da identidade docente como uma categoria histórica e culturalmente situada, a terceira discute os saberes docentes na perspectiva da experiênciaprofissional e, por fim, a quarta tese foca a autonomia dos docentes diante do 
desenvolvimento científico e tecnológico e das regulações do modelo gerencial das instituições de ensino.

Do estudo dessas teses, os referidos autores concluem que a formação de professores da EPT não se esgota na posse de "credenciais acadêmicas", mas se constitui na dinâmica da cultura profissional e na reflexividade presentes na experiência, nos processos de construções identitárias e na autonomia dos grupos profissionais perante os dilemas e as pressões exercidas pelo desenvolvimento científico e tecnológico.

Essa constatação elucida alguns aspectos necessários para os estudos sobre a formação de professores da Educação Profissional e Tecnológica, quais sejam: a especificidade de cada uma das profissões quando se analisa o processo de crise pelo qual elas vêm passando; a valorização dos saberes e da experiência dos professores, estabelecendo uma relação coerente entre educação, trabalho e tecnologia; valorização das ações e de tomada de decisão dos professores, auxiliandoos na reflexão e na construção de atitudes que "concorram para definir o que tem e o que não tem valor na vida pessoal, profissional e em sociedade." (FARTES e SANTOS, 2011, p.399).

Diante do exposto, destacamos a importância de entender a formação pedagógica dos professores na perspectiva da cultura docente, pois esta se constitui em crenças, hábitos e normas que orientam as ações dos professores na escola e definem seus modos de pensar e agir. Os estudos sobre essa temática, assim, podem contribuir para os processos de formação inicial e continuada dos docentes da Educação Profissional e Tecnológica (EPT), proporcionando mudanças nas práticas desses profissionais.

\subsection{Influências e contribuições da formação continuada para a prática docente}

Neste tópico, apresentamos as pesquisas que tratam da formação de professores da Educação Profissional e Tecnológica (EPT), destacando as influências e contribuições da formação continuada para a prática docente (OLIVEIRA, 2011; CARPIM, 2011; BARBACOVI, 2011; CUNHA, 2012; KASPER, 2011; ARAÚJO, 2010; PEREZ, 2010; QUADROS, etall, 2010; GOMES, 2004; SANTOS; FIGHERA;JUCHEM, 2012).

Os estudos partem do pressuposto de que o avanço tecnológico e suas constantes mudanças têm provado profundos impactos educacionais, sociais e econômicos, notadamente, na educação profissional, na medida em que surgem políticas governamentais que visam promover uma formação profissional situada com o mundo do trabalho. Consequentemente, novas demandas são postas em relação à formação continuada dos professores que precisam de uma sólida fundamentação teórica e prática para enfrentar os desafios da sociedade atual.

A pesquisa realizada por Gomes (2004) acerca das percepções, expectativas e desejos dos professores sobre as transformações ocorridas na educação profissional de nível médio, buscou entender como o processo de formação contínua pode orientar e impulsionar os processos de mudanças na instituição de ensino. Consequentemente, ajudar os docentes a enfrentarem as dificuldades de seu cotidiano de trabalho. Esse estudo evidenciou que essa formação é um 
processo que necessita de tempo, maturidade, apoio institucional, crédito e crença na profissão pela sociedade e pelos profissionais da educação.

Oliveira (2011) acrescenta que a formação continuada em serviço constitui-se como uma opção para que os professores da educação profissional possam refletir sobre sua atuação e possam construir um melhor entendimento das demandas da profissão docente. A formação continuada segundo a autora abrange todos os eventos do cotidiano de trabalho, desde uma reunião de curso, até uma formação realizada por profissionais externos à instituição.

Baseada nessa compreensão, Oliveira (2011) realizou uma pesquisa com o objetivo de analisar o papel da formação continuada nos processos de produção, apropriação e socialização dos saberes dos docentes. Os dados da investigação revelam as possibilidades desse processo formativo para a melhoria das práticas pedagógicas dos professores, mas apontam limites para a realização dessa formação os quais estão intrinsecamente relacionados à dinâmica dos trabalhos na instituição, rotina intensa de trabalho, número reduzido de docentes em algumas áreas profissionais, além da falta de recursos financeiros.

Ancorada nos pressupostos do paradigma da complexidade, Carpim (2011) optou por realizar um estudo de caso no intuito de identificar as intenções, valores e os sentidos reais dos professores participantes de um curso de formação pedagógica. Os resultados da investigação revelam as possibilidades do curso de formação continuada contribuir para o aprimoramento dos conhecimentos didáticos e pedagógicos para a educação profissional. Embora os professores "tenham sido formados atendendo aos paradigmas tradicionais de ensino com os pressupostos reducionistas e cartesianos, estão receptivos quanto a mudar sua prática educativa." (CARPIM, 2011, p,163-164).

Kasper (2011) ao realizar uma pesquisa-açãojunto a professores dos cursos técnicos em Administração e Informática de uma escola de Educação Profissional particular também identificou a contribuição dos cursos de formação continuada para a melhoria das práticas docentes. Os resultados da pesquisa revelam que os processos formativos oferecidos pela instituição de ensino podem favorecer a mudança de atitudes dos professores, aumento de autoestima, ampliação do compromisso, inovação das aulas, sustentadas na relação teoria e prática, desenvolvimento de lideranças pedagógicas, além de uma melhor compreensão das repercussões das transformações do mundo atual no seu contexto de trabalho.

Cunha (2012), ao realizar uma pesquisa no intuito de analisar a formação pedagógica desenvolvida em um programa de formação continuada para professores da área estética constata que tal programa contribuiu para o desenvolvimento das atividades dos docentes. 0 estudo revelou também que a formação continuada contribuiu para a compreensão da relação conteúdo e método, possibilidade de uso de novas estratégias de ensino, melhoria na relação professor/aluno, mas que há necessidade de aprofundamento de questões relativas à organização do planejamento de ensino e à avaliação da aprendizagem.

O reconhecimento e a valorização da formação continuada também são contatados nos resultados da pesquisa de Araújo (2010) que visou investigar o significado, as demandas, as limitações e as expectativas de formação continuada dos professores de uma escola pública de 
ensino técnico. Apesar desse reconhecimento, os professores apontaram alguns entraves, como a sobrecarga de trabalho, os baixos salários, a falta de apoio financeiro e de políticas institucionais, além da situação de desprestígio do ensino técnico e da correlata desvalorização dos professores da área, constatação também encontrada nas investigações de Carpim(2011) e Oliveira (2011).

O estudo de Barbacovi (2011) também destaca fatores que compõem o processo de formação para a prática docente. O referido autor aborda a temática buscando estabelecer uma relação entre as concepções educacionais dos professores que sustentam sua prática e seu perfil formativo (cursos feitos e sua avaliação acerca do curso de graduação) e sua postura ante os saberes docentes. Ou seja, estuda a temática considerando o interesse de indagar e refletir sobre o perfil desse profissional tendo como foco o trabalho por ele desenvolvido.

Os dados da investigação de Barbacovi (2011) revelam que o processo de constituição da formação docente dos professores é marcado, predominantemente, pela prática profissional que desenvolvem e estes reconhecem a pouca importância da formação inicial ou continuada nessa constituição. O referido autor destaca: "a prática docente dotada dos seus sentidos intrínsecos relações simbióticas entre teoria e prática - é que dá sustentação e firmeza ao próprio processo de formação docente que é contínuo e se faz para além dos cursos formais institucionalmente apresentados." (p.226).

Barbacovi (2011), nesse sentido, considera que a possibilidade dos professores construírem uma prática reflexiva está relacionada com a forma destes perceberem suas próprias trajetórias, na forma de se apropriarem dos conhecimentos disponibilizados e/ou construídos, sejam eles acadêmicos, experienciais, técnicos, pedagógicas - e na forma deles compreenderem a própria prática - fechada em si mesma ou aberta a novos diálogos entre os diferentes saberes.

A contribuição da formação continuada para a prática docente também está relacionada com a visão e o modelo de formação que norteia o processo de capacitação e desenvolvimento de professores. Essa temática foi investigada por Perez (2010) que buscou analisar um programa de formação realizado por uma organização de educação profissional, que possui uma rede de escolas no Estado de São Paulo. Os dados desse estudo apontaram que o modelo de formação adotado é o reflexivo, baseado nos escritos de Donald Shon, favorecendo as possibilidades de construção coletiva de saberes sobre o trabalho docente.

$\mathrm{Na}$ perspectiva de contribuir para a formação de professores para a Educação Profissional,Quadros etall (2010) apresenta um artigo que trata de um relato de experiência a partir da oferta de um Programa Especial de Formação Pedagógica de Docentes para a Educação Profissional. O relato destaca a importância da interdisciplinaridade nos currículos dos cursos de formação docentes para o Ensino Médio integrado ao Ensino Técnico. Os estudos de Santos, Fifhera e Juchem (2012) também alertam que essa formação não deve "ficar limitada aos aspectos práticos (didáticos ou metodológicos) do cotidiano da sala de aula, todavia precisaria abranger dimensões relativas às questões éticas, afetivas e político-sociais envolvidas no fazer docente." (p.8) 
Os estudos apresentados neste tópico nos permitiram visualizar um conjunto de investigações científicas que tiveram como foco experiências institucionais de formação continuada de professores com a finalidade de contribuir para a melhoria das práticas docentes.

Os resultados das investigações destacam que os processos formativos dos professores elucidam um caminho para a superação de uma concepção de educação profissional pautada numa racionalidade técnica, consequentemente, de práticas docentes que se traduzem em reprodução do conhecimento, visando apenas à inserção dos estudantes do mercado de trabalho. Por outro lado, é preciso atentar-se aos limites dessa formação nas instituições de ensino os quais estão relacionados ao contexto de trabalho no qual os docentes estão inseridos.

Considerando que nosso objeto de estudo é a formação pedagógica dos professores e sua influência na prática docente na Educação Profissional e Tecnológica, o panorama das pesquisas ora apresentado aponta a importância de compreender as contradições do contexto de trabalho dos professores, os sentidos e significados que esses profissionais atribuem às suas práticas em sala de aula, bem como as concepções subjacentes a esses processos formativos e a essas práticas.

\subsection{Formação de professores sob o enfoque das políticas públicas}

No campo das políticas educacionais, encontramos dois trabalhos: Orso (2011) que trata das políticas de formação de professores para os cursos técnicos em Nível Médio, especialmente, nas disciplinas profissionalizantes, e Costa (2012) que aborda as políticas de formação de professores para a Educação Profissional e Tecnológica, formuladas e promulgadas a partir da expansão da Rede Federal de Educação Profissional, Científica e Tecnológica (RFEPCT).

Orso (2011) desenvolve suas reflexões a partir de sua trajetória acadêmica onde encontrou professores bacharéis que lecionavam as disciplinas profissionalizantes do curso técnico, sem possuírem formação pedagógica, e que não consideravam a docência como profissão, e sim, como uma segunda atividade. Essa situação levou a referida autora a se questionar como, historicamente, se desenvolveram as políticas educacionais de formação de professores das disciplinas profissionalizantes dos cursos técnicos de nível médio no Brasil e, especialmente, no Paraná, no período de 1971 a 2008. Para alcance de seus objetivos, Orso (2011) realiza uma pesquisa documental, destacando leis, decretos pareceres e portarias ministeriais que davam sustentação ao estudo da temática.

Os achados do estudo revelam que as leis elaboradas para a formação de professores das disciplinas profissionalizantes dos cursos técnicos em nível médio "não deram conta de formar a quantidade necessária de professores habilidades para esta modalidade de ensino". (ORSO, 2011, p.155).O Estado do Paraná, especificamente, buscou suprir essa demanda através de convênios desenvolvidos com instituições de ensino superior por meio dos programas especiais de formação pedagógica, mas ainda apresenta um número significativo de docentes que não tem qualificação 
adequada para atuar nessa área. Diante dessa análise histórica, Orso (2011) destaca que houve pouco avanço na consolidação de políticas para a formação de professores para a EPT.

Costa (2012), de acordo com suas análises documentais,entende que não há uma política de formação docente voltada para EPT, pois esta, historicamente, é "marcada por programas efêmeros, emergenciais, imediatistas, visando suprir a falta de professores qualificados (licenciados ou egressos dos cursos de formação especial para professores) para o exercício da docência no ensino técnico." (COSTA, 2012, p.18).

A ausência dessa política de formação de professores se agrava diante do quadro crescente de expansão da Rede Federal de Educação Profissional, Científica e Tecnológica RFEPCT, por meio da implantação dos Institutos Federais de Educação e Tecnológicas - IFETs onde cada vez mais ingressam profissionais que podem atuar em cursos técnicos, de graduação e pós-graduação.

Nesse contexto, podemos afirmar que, apesar da expansão da Rede federal de Educação Profissional, as políticas de formação de professores para a EPT ainda não se materializaram, sendo estas realizadas em programas numa lógica de percursos "descontínuos, reducionistas, aligeirados e emergenciais" (COSTA, 2012, p. 201). Diante desse cenário, surge a necessidade de ampliação dos estudos nessa área a fim de contribuir para a elaboração e implementação de políticas públicas que visem à valorização da profissão docente da EPT, cujos processos formativos devem ser pautados sob o tripé: ensino, pesquisa e extensão.

A partir da análise dos trabalhos sobre a formação de professores da EPT, apresentamos a seguir as principais contribuições apontadas pelos estudos mapeados, buscando identificar novas perspectivas de investigação nessa área.

\section{CONSIDERAÇÕES: A ELUCIDAÇÃO DA FORMAÇÃO DE PROFESSORES PARA A EDUCAÇÃO PROFISSIONAL E TECNOLÓGICA DOS ESTUDOS MAPEADOS}

Nossa intenção neste artigo foi apresentar o estado atual da produção científica relacionada à temática Formação de Professores da Educação Profissional e Tecnológica (EPT), no período de 2005 a 2014.

O mapeamento dos trabalhos científicos realizado no portal da CAPES, nas reuniões anuais da ANPED e no ENDIPErevela a carência de investigações acerca da educação profissional na perspectiva da formação docente, remetendo a necessidade de realização de estudos acerca dessa temática.

As investigações analisadas ao tratarem da formação de professores da EPT tendem a considerar a prática um elemento fundamental tendo em vista que é no fazer do professor que identificamos suas dificuldades, seus desafios, bem como as suas estratégias de superação. Assim, é possível pensar na formação continuada dos docentes como uma ação que visa refletir sobre as práticas pedagógicas, buscando minimizar as dificuldades enfrentadas nas mesmas, além de avançar na compreensão histórica dos processos da formação humana em suas articulações com a 
vida social e produtiva, aliada às teorias pedagógicas. Essa evidência traz à tona a importância de considerarmos o "trabalho docente" como categoria central para a compreensão dessa temática, remetendo à necessidade de entendermos a formação pedagógica dos professores, configurada na prática,bem como identificar as concepções que a orientam. Buscamos, assim, estabelecer uma relação dialética entre o que pensam e fazem os docentes.

Os estudos analisados também destacam a importância das instituições de ensino superior organizarem espaços de formação continuada, assumindo a responsabilidade de sustentação do desenvolvimento profissional dos professores como prioridade necessária, a partir de uma base epistemológica e metodológica que fundamentem essa formação. Os resultados apontam, ainda, algumas pistas nesse sentido, como: o conceito de práxis; a pedagogia do trabalho; a interação entre o mundo do trabalho, a ação pedagógica e o conhecimento científico e tecnológico; os saberes docentes, superando a dicotomia existente entre conteúdo específico e conteúdo pedagógico, dentre outros aspectos.

Esses achados nos permitem considerar pertinente o aprofundarmos dos estudos nesse campo além de apontarem para a necessidade do estabelecimento de uma política de formação pedagógica para os professores da EPT de nível superior.

\section{REFERÊNCIAS}

ARAÚJO, Tânia Márcia Fernandes de. (2004).A formação continuada segundo os professores do ensino técnico. In. XII ENDIPE - Encontro Nacional de Didática e Práticas de Ensino. Curitiba: Pontifícia Universidade Católica do Paraná - Curitiba/PR.

BARBACOVI, Lecir Jacinto. (2011). O professor de educação profissional e a conectividade orgênica entre formação e pratica docente. Tese (Doutorado) - Universidade Federal de Minas Gerais, Belo Horizonte.

BRASIL.(2016). Lei n. 9.394, de 20 de dezembro de 1996. Estabelece as Diretrizes e Bases da Educação Nacional. Diário Oficial da União.Brasília, DF, ano134, n. 248, p. 27833-27841, dez.

. (2006). Conselho Nacional de Educação/Câmara de Educação Superior. Parecer no 05/2006. Aprecia a indicação do CNE/CP no 2/2002 sobre as Diretrizes Curriculares Nacionais para os Cursos de Formação de Professores para a Educação Básica.

.MEC. SEMTEC. (2003). Seminário nacional de educação profissional. "Concepções, experiências, problemas e propostas". Documento-base. Brasília: MEC/SEMTEC/PROEP.

.MEC/SETEC. (2004). Proposta em discussão. Políticas públicas para a Educação Profissional e Tecnológica. Brasília: Secretaria de Educação Profissional e Tecnológica, Ministério 
da Educação.

- (2012). Conselho Nacional de Educação. Câmara da Educação Básica.Resolução CNE/CEB no 6 de 20 de setembro de 2012. Define as Diretrizes Curriculares Nacionais para a Educação Profissional Técnica de Nível. Diário Oficial da União, Brasília. Disponível em: <http://portal.mec.gov.br/index.php?option=com_content\&view=article\&id=17417\&ltemid=866. Acesso em: 22 out. 2015

. (2014). Lei no 13.005 de 25 de Junho de 2014. Aprova o Plano Nacional de Educação PNE e dá outras providências. Diário Oficial da União. Brasília. Disponível em: http://www.planalto.gov.br/ccivil_03/_ato2011-2014/2014/lei//13005.htm. Acesso em: 22 out. 2015

BURNIER, Suzana. (2006). A docência na Educação Profissional.In: 29 REUNIÃO DA ANPED. Trabalhos apresentados. Caxambu, MG.

; GARIGLIO, José Ângelo. (2010).Uma aproximação inicial aos saberes da docência da educação profissional. In: XV ENDIPE - Encontro Nacional de Didática e Prática de Ensino. Belo Horizonte: Universidade Federal de Minas Gerais.

CARDOSO, Aliana Anghinoni. (2012). Professores? Sim! Os saberes docentes e os professores da educação profissional. Dissertação (Mestrado) - Universidade Federal de Pelotas, Pelotas.

CARPIM, Lucymara. (2011).Formação pedagógica dos professores do ensino técnico: caminhos históricos para um paradigma da complexidade. Dissertação (Mestrado) - Pontifícia Universidade Católica do Paraná, Curitiba.

CASTELLS, Manuel. (1999).A sociedade em rede. São Paulo: Paz e Terra.

COSTA, Maria Adelia da. (2012).Políticas de formação de professores para a educação profissional e tecnológica: cenários contemporâneos. Tese (Doutorado) - Universidade Federal de Uberlândia, Uberlândia.

CUNHA, Marlise Pinheiro da. (2012).Formação continuada do professor do ensino técnico em Estética. Dissertação (Mestrado) - Pontifícia Universidade Católica do Paraná, Curitiba. 
DURÃES, Marina Nunes. (2010).O professor da educação profissional: sua origem, formação e relação com a docência. XV ENDIPE - Encontro Nacional de Didática e Prática de Ensino. Belo Horizonte: Universidade Federal de Minas Gerais.

FARTES, Vera; SANTOS, Adriana Paula Q. Oliveira. (2011). Saberes, identidades, autonomia na cultura docente da educação profissional e tecnológica. Cadernos de Pesquisa, São Carlos, v. 41, n. 143, p.376-401.

FORTES, Maria Carolina. (2012).Entrelaçados de vidas: A constituição da docência na educação profissional e tecnológica. Tese (Doutorado) - Pontifícia Universidade Católica, Porto Alegre, 2012.

GARIGLIO, José Ângelo; BURNIER, Suzana. (2012). Saberes da docência na educação profissional e tecnológica: um estudo sobre o olhar dos professores. Educação em Revista, [s.l.], v. 28, n. 1, p.211-236, mar.

GOMES, Heloisa Maria. (2004).Formando professores para a educação profissional.In: 27 REUNIÃO DA ANPED. Trabalho Apresentados. Caxambu, MG.

IMBERNON, F. (2000).Formação docente e Profissional: Formar-se para a mudança e a incerteza. São Paulo: Cortez.

KUENZER, Acácia. (2008). Mesa redonda. Formação de professores para a educação profissional e tecnológica: perspectivas históricas e desafios contemporâneos. Formação de Professores para Educação Profissional e Tecnológica: Brasília: Instituto Nacional de Estudos e Pesquisas Educacionais Anísio Teixeira, pp. 19-40.

(2006). A educação profissional nos anos 2000: a dimensão subordinada das políticas de inclusão. Revista Educação e Sociedade, Campinas, vol. 27, n. 96 - Especial, p. 877-910, out.

MACHADO, Lucília Regina de Souza. (2011).O desafio da formação dos professores para a EPT e PROEJA. Revista Educação e Sociedade, Campinas, v. 32, n. 116, p. 689-704, jul.-set.

. (2008).Diferenciais inovadores na formação de professores para a educação profissional.Revista Brasileira da Educação Profissional e Tecnológica. Brasília, jun.

MARTINS, Leticia Aparecida. (2011).Trajetória de constituição da docência na educação profissional. Dissertação (Mestrado) - Universidade de Campinas, Campinas. 
MOREIRA, Alexandre. (2012).Formação e atuação do bacharel-professor na área de telecomunicações do Instituto Federal de Santa Catarina. Dissertação (Mestrado) - Universidade Federal de Santa Catarina, Florianópolis.

NÓBREGA-THERRIEN, SILVIA MARIA; THERRIEN, JACQUES. (2004).Os trabalhos científicos e o estado da questão: reflexões teórico-metodológicas. Estudosem avaliação educacional. Fundação Carlos Chagas .v. 15. n, 30. p.5-16, jul/dez.

NUNES, Terezinha de Souza Ferraz. (2012).A constituição da docência nos cursos superiores de tecnologia: implicações do discurso pedagógico oficial. In: 35 REUNIÃO DA ANPED. Porto de Galinhas. Trabalhos apresentados, Porto de Galinhas, PE.

OLIVEIRA, Maria Rita Sales. (2006).Formação e profissionalização dos professores do ensino técnico. In: XIII ENDIPE - Encontro Nacional de Didática e Práticas de Ensino. Recife: Universidade Federal de Pernambuco.

OLIVEIRA, Nelda Plentz de (2011).Formação continuada de professores e o desenvolvimento de currículos integrados na educação profissional e tecnológica. Tese (Doutorado) - Universidade de Campinas, Campinas.

ORSO, Ana Paula Grochocki. (2011).As políticas educacionais de formação de professores dos cursos técnicos em nível médio: cursos profissionalizantes no Paraná. Dissertação (Mestrado) Pontifícia Universidade Católica do Paraná, Curitiba.

PAIVA, Cantaluce, Mércia Ferreira. (2012).A identidade docente na educação profissional: como se forma o professor.In: 35 REUNIÃO DA ANPED. Porto de Galinhas. Trabalhos apresentados. Porto de Galinhas, PE.

PEREZ, Deivis. (2010). Paradigmas de formação: estudo sobre um modelo de capacitação e desenvolvimento de professores para a educação profissional. XV ENDIPE - Encontro Nacional de Didática e Práticas de Ensino. Belo Horizonte: Universidade Federal de Minas Gerais.

PIMENTA, S. G. (2009). Formação de professores: identidade e saberes da docência. In: PIMENTA, S. G. (Org.). Saberes pedagógicos e atividade docente. 7ạ ed. São Paulo: Cortez, p. 15-34.

QUADROS, Claudemir de.; Santos, Leila Maria Araújo; Rodrigues, Maria Luiza; Barichello, Marta Roseli de Azeredo. (2010). Interdisciplinaridade na formação pedagógica de docentes para a 
educação profissional: algumas aproximações. XV ENDIPE - Encontro Nacional de Didática e Prática de Ensino. Belo Horizonte: Universidade Federal de Minas Gerais.

SANTOS, patrícia penha dos. (2011).Formação continuada de educadores: um olhar focado na educação profissional e nas movimentações das tecnologias da comunicação e informação. Dissertação (Mestrado) - Centro Universitário La Salle, Canoas.

SANTOS, Luciana Dalla Nora dos; FIGHERA, Adriana Cláudia Martins; JUCHEM, Luiza de Salles (2012). A formação pedagógica do professor da educação profissional e tecnológica. XVI ENDIPE Encontro Nacional de Didática e Prática de Ensino. Campinas: Universidade Estadual de Campinas.

SIMIONATO, Margareth Fadanelli. (2011). A formação do professor do ensino técnico e a cultura docente. Tese (Doutorado) - Universidade Federal do Rio Grande do Sul, Porto Alegre.

URBANETZ, Sandra Terezinha. (2011). A constituição do docente para a educação profissional. Tese (Doutorado) - Universidade Federal do Paraná, Curitiba. 